

\title{
EDITORIAL AS 50
}

\section{ARQUITECTURA PUBLICADA}

\author{
PUBLISHED ARCHITECTURE
}

Estos 50 números editados por Arquitecturas del Sur, que aquí conmemoramos, confirman ante todo el compromiso sostenido que la Universidad del Bío-Bío ha desplegado con la generación y divulgación de nuevo conocimiento disciplinar a través de las publicaciones periódicas. Este esfuerzo, concretamente desarrollado durante 33 años en Arquitecturas del Sur, queda refrendado a nivel continental, en la osadía de liderar el proyecto de la Red Asociación de Revistas Latinoamericanas de Arquitectura que cuenta hoy con 77 publicaciones asociadas, pertenecientes a 10 países .

Publicar el significativo $n^{\circ} 50$ exige sostener una mirada crítica acerca de nuestro trabajo, observar con cautela los logros y reconocimientos obtenidos para trazar criteriosamente nuevas metas que nos permitan optimizar el nivel de nuestros contenidos, y, desde luego, resguardar la calidad de la experiencia que otorgamos a los autores que nos confían sus escritos.

En el II Encuentro de editores ARLA, celebrado en la Universidad de Buenos Aires en agosto del presente año, se discutió precisamente en torno a las características que definen la especificidad de las publicaciones de nuestra disciplina con la intención de formalizar nuestros propios estándares de calidad, asegurando, de esa manera, la pertinencia de estos considerables esfuerzos editoriales. Se subrayó, en ese tenor, la importancia que deben tener los aspectos cualitativos de las revistas de arquitectura y urbanismo, ya que estas tienen como misión difundir aportes que provienen del ámbito de la creación como fuente de conocimiento. Se planteó también que es imprescindible desarrollar y precisar la particularidad de nuestras propuestas editoriales, salvaguardando siempre su coherencia. Estas miradas o focos de atención de las diferentes publicaciones, constituyen, sin duda y en su conjunto, una amplia e invaluable experiencia de aproximación al entendimiento del conocimiento arquitectural. Es por esta razón que en esta reunión se confirmó que la diversidad es uno de los principales valores de ARLA, que, en tal sentido, ha rechazado conscientemente la posibilidad de constituirse como un índice selectivo, reforzando así su carácter inclusivo y depositando su confianza en las virtudes del trabajo colaborativo como estrategia permanente de superación.

Hemos decidido celebrar nuestros 50 números, y -por cierto- nuestra reciente indexación en el Emerging Source Citation Index de Web of Science, con el tema "Arquitectura publicada", que reúne seis trabajos cuyos objetos de investigación son las propias revistas de arquitectura. Constituye, a su vez, un sencillo homenaje a cada una de las personas que han contribuido generosamente con Arquitecturas del Sur desde su creación en 1983, y a todos los equipos editoriales de las revistas latinoamericanas que, con inagotable entusiasmo, visualizan cada año una nueva meta a alcanzar en el horizonte.

Hernán Ascui Fernández 